\title{
ANALISIS KUALITAS PRODUK PERTH PX DI PT. ASRI PANCAWARNA
}

\author{
Tri Widodo dan Nur Fadilah Fatma \\ Program Studi Teknik Industri, Universitas Muhammadiyah Tangerang \\ e-mail: tiga_wd@yahoo.co.id
}

\begin{abstract}
ABSTRAK
Kualitas merupakan keseluruhan karakteristik dan keistimewaan dari suatu produk atau jasa yang dihasilkan dari kemampuan produk atau jasa untuk memuaskan sebagian atau secara keseluruhan kebutuhan dari konsumen. PT. Asri Pancawarna adalah salah satu perusahaan yang bergerak di bidang manufaktur, khususnya Granite Tile. Namun masih terjadi beberapa masalah dalam proses produksinya, seperti tingginya defect pada salah satu produk yang di produksi PT. Asri Pancawarna yaitu produk Perth PX. Penelitian ini bertujuan untuk mengetahui bagaimana penerapan pengendalian kualitas menurunkan jumlah produk cacat. Terdapat lima jenis cacat/deffect yang ada di departemen Quality Assurance yaitu, jenis cacat Cekung, chipping, Lainasi, Belang dan Cembung. Jenis cacat yang paling dominan adalah jenis cekung dengan persentase yang cukup besar yaitu mencapai 45,35\% untuk produk Pert PX. Penyebab utamanya adalah karena material powder yang masih ada kadar air, udara yang masih terperangkap dalam keramik, proses pembakaran yang tidak merata serta suhunya terlalu tinggi dan proses pendinginan yang tidak berlangsung lama sehingga pada proses polesing permukaan keramik menjadi turun/cekung. Solusi yang bisa diterapkan untuk menanggulangi faktor manusia diantaranya dengan melakukan pelatihan yang teratur secara berkala, memilih operator yang masih muda dengan tingkat ketelitian yang masih baik. Serta lingkungan atau ruangan yang mendukung seperti, pencahayaan dan temperature ruang yang baik serta mengurangi tingkat kebisingan.
\end{abstract}

Kata kunci: Fish Bone, Pareto, Produk perth PX, kualitas.

\begin{abstract}
Quality is an overall characteristics and features of a product or service resulting from the ability of a product or service to satisfy in part or as whole needs of consumers. PT. Asri Pancawarna is one of the companies engaged in manufacturing, particularly Granite Tile. But there are still some problems in the production process, such as high defect on one of the product in the production of PT. Asri Pancawarna namely Perth PX product. This study aims to determine how the applications of quality control decrease the number of defective products. There are five types of defects in the department of Quality Assurance that is, the type of defect Concave, chipping, Lainasi, mottle and Convex. The most dominant defect type is the type concave with a considerable percentage reaching $45.35 \%$ for products Pert PX. The main reason is because the powder material remaining moisture content, the air is still trapped in the ceramic, the combustion process is uneven and too high temperature and cooling processes that do not last long so that the process polishing ceramic surface to be down / concave. A workable solution to address the human factor among others by conducting regular training on a regular basis, choose a provider that is still young with a level of accuracy that is still good. As well as supporting the environment or space, such as lighting and good room temperature as well as reducing the noise level.
\end{abstract}

Keywords: Fish Bone, Pareto, Perth PX Product, Qualities.

\section{PENDAHULUAN}

Kualitas merupakan keseluruhan karakteristik dan keistimewaan dari suatu produk atau jasa yang dihasilkan dari kemampuan produk atau jasa untuk memuaskan sebagian atau secara keseluruhan kebutuhan dari konsumen. Konsumen sebagai pemakai produk semakin kritis dalam memilih atau memakai produk, keadaan ini mengakibatkan peranan kualitas semakin penting. Berbagai macam metode dikembangkan untuk mewujudkan suatu kondisi yang ideal dalam sebuah proses produksi, yaitu zero defect atau tanpa cacat.

PT. Asri Pancawarna adalah salah satu perusahaan yang bergerak di bidang manufaktur, khususnya granite tile. Pasarnya terdiri dari pasar domestic dan internasional. Dalam proses produksinya masih ditemukan beberapa masalah kualitas, seperti chipping, gelembung, retak dan lain sebagainya. Dengan menganalisis kualitas dari setiap prosesnya 
dengan menggunakan tools kualitas akan mengetahui faktor-faktor apa saja yang mempengaruhi kualitas yang menjadi akar penyebab masalah dari proses produksi granite tile, sehingga dapat menentukan tindakan perbaikan yang tepat untuk memperbaiki kualitas produksi sepatu tersebut serta meminimalkan jumlah defect yang terjadi pada proses produksi sehingga akan menghemat biaya, waktu dan tenaga dan menjadikan kepuasan tersendiri bagi pelanggan.

Berdasarkan latar belakang yang diuraikan di atas, maka tujuan dari penelitian ini adalah untuk mengetahui defect apa saja yang ada pada produk Perth PX, Untuk mengetahui defect terbesar pada produk perth PX dan untuk menemukan penyebab defect pada produk perth PX.

Kualitas merupakan salah satu indikator penting bagi perusahaan untuk dapat eksis di tengah ketatnya persaingan dalam industri. Kualitas di definisikan seagai totalitas dari karakteristik suatu produk yang menunjang kemampuannya untuk memuaskan kebutuhan yang di spesifikasikan atau di tetapkan.

Pada dasarnya Manajemen Kualitas (Quality Management) atau manajemen kualitas terpadu (TQM) didefinisikan sebagai suatu cara meningkatkan perfomansi secara terus menerus pada setiap level operasi atau proses, dalam setiap area fungsional dari suatu organisasi dengan menggunakan semua sumber daya manusia dan modal yang tersedia.

Tanggung jawab untuk manajemen kualitas ada pada semua level dari manajemen, tetapi harus di kendalikan oleh manajemen puncak (Top Management) dan implementasinya harus melibatkan semua anggota organisasi.

Pengendalian dalam istilah industri dapat diidentifikasikan sebagai suatu proses untuk mendelegasikan tanggung jawab dan wewenang untuk kegiatan manajemen sambil tetap menggunakan cara-cara untuk menjamin hasil yang memuaskan [1].

Pengendalian adalah sebagai keseluruhan cara yang digunakan untuk menentukan dan mencapai standar. Apabila ingin memutuskan untuk melaksanakan sesuatu, dimulai dengan sebuah rencana, kemudian bekerja menurut rencana tersebut, dan meninjau kembali hasilnya. Pengendalian merupakan semua kegiatan atau usaha menjamin agar hasil dari pada pelaksana sesuai dengan tujuan yang telah ditetapkan dalam rencana [2].

Menurut Kaoru Ishikawa QA adalah kegiatan untuk memastikan mutu dalam suatu produk sehingga pelanggan dapat membelinya dengan keyakinan dan kepuasan.

Menurut ISO 8402 QA adalah semua kegiatan yang terencana dan sistematis yang diterapkan di dalam sistem mutu dan dilaksanakan sesuai dengan kebutuhan, untuk memberikan keyakinan yang cukup bahwa perusahaan akan memenuhi persyaratan mutu [3].

$\mathrm{QA}=$ Quality Assurance, to lead and operated by assure of an organization successfully, it is necessary to direct and control it in a systematic and transparent manner. Maksudnya adalah meyakinkan/ menjamin secara kualitas dengan suatu sistematis kerja dan keterbukaan untuk keberhasilan suatu pekerjaan secara keseluruhan organisasi di setiap lini dengan melalui sistem control.

Satu hal yang perlu dipertimbangkan yakni "Jangan meng-eliminir Inspection" karena Inspection adalah salah satu cara untuk memastikan produk. Untuk memastikan produk memang tidak hanya dengan Inspection saja, masih ada cara lainnya yakni: Process Control Oriented dan Product Development Oriented. Tergantung dari karakteristik produk masingmasing untuk menentukan cara mana yang paling efektif.

Manajemen Kualitas seringkali disebut sebagai the problem solving, sehingga manajemen kualitas dapat menggunakan metodologi dalam problem solving tersebut untuk mengadakan perbaikan [4]. Ada berbagai teknik perbaikan kualitas dalam organisasi yaitu dengan menggunakan 7 alat bantu (seven tools). Tujuh alat dasar quality management merupakan pendekatan yang sangat praktis dan sangat mudah untuk diimplemantasikan, sehingga sangat layak untuk digunakan pada tingkat pelaksana. Pada level yang lebih tinggi, pemecahan masalah tidak sekedar pada masalah yang sudah jelas diketahui, tetapi juga terhadap 
potensi masalah, atau terhadap kemungkinan akan munculnya masalah dari suatu program. Tujuh alat baru ini merupakan jawaban atas tuntutan di atas.

\section{METODELOGI PENELITIAN}

Berikut adalah diagram alir penelitian yang telah dilaksanakan.

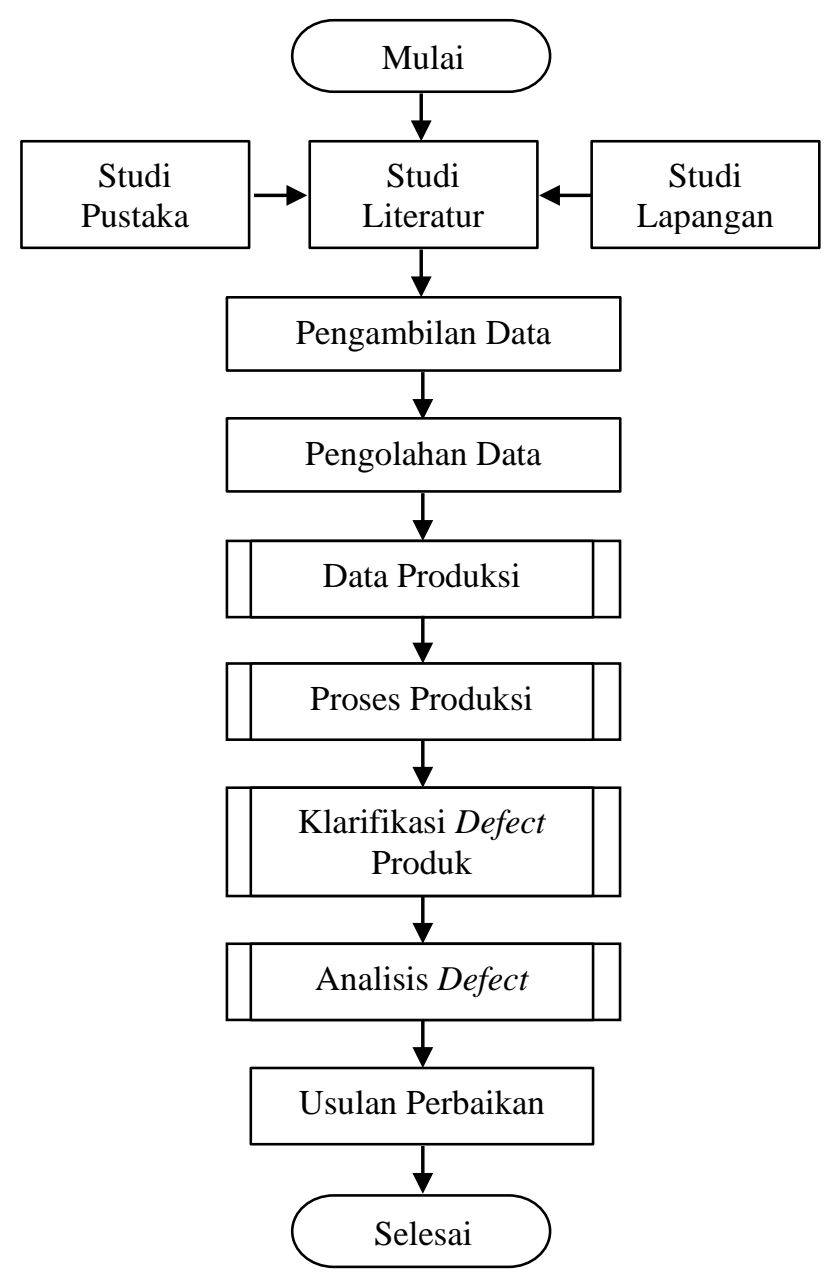

Gambar 1. Diagram Alir Penelitian

\section{ANALISIS DAN PEMBAHASAN Pengumpulan Data dan Klasifikasi Data}

Tabel 1. Data Produksi Produk Perth PX Bulan Januari-Februari 2016 Selama 19 hari

\begin{tabular}{rrrrrrr}
\hline No & Tanggal & KW1 & KW2 & KW3 & reject & $\begin{array}{c}\text { Total } \\
\text { Production }\end{array}$ \\
\hline 1 & 11 Jan & 132 & 56 & 4 & 16 & 208 \\
& 2016 & & & & & 7.952 \\
2 & 12 Jan & 6356 & 1024 & 344 & 228 & \\
2016 & & & & & 4.540 \\
3 & 15 Jan & 3868 & 308 & 244 & 120 & 4016 \\
\hline
\end{tabular}

Lanjutan Tabel 1. Data Produksi Produk Perth PX Bulan Januari-Februari 2016 Selama 19 hari

\begin{tabular}{|c|c|c|c|c|c|c|}
\hline \multirow[b]{2}{*}{ No } & \multirow[b]{2}{*}{ Tanggal } & \\
\hline & & KW1 & KW2 & KW3 & reject & $\begin{array}{c}\text { Total } \\
\text { Production }\end{array}$ \\
\hline 4 & $\begin{array}{r}16 \text { Jan } \\
2016\end{array}$ & 2000 & 292 & 168 & 100 & 2.560 \\
\hline 5 & $\begin{array}{r}18 \text { Jan } \\
2016\end{array}$ & 3812 & 644 & 76 & 140 & 4.672 \\
\hline 6 & $\begin{array}{r}19 \text { Jan } \\
2016\end{array}$ & 2112 & 2548 & 336 & 332 & 5.328 \\
\hline 7 & $\begin{array}{r}20 \text { Jan } \\
2016\end{array}$ & 2432 & 372 & 164 & 164 & 3.132 \\
\hline 8 & $\begin{array}{r}21 \text { Jan } \\
2016\end{array}$ & 2184 & 84 & 76 & 200 & 2.544 \\
\hline 9 & $\begin{array}{r}22 \text { Jan } \\
2016\end{array}$ & 200 & 0 & 8 & 16 & 224 \\
\hline 10 & $\begin{array}{r}23 \text { Jan } \\
2016\end{array}$ & 4.184 & 432 & 192 & 240 & 5.048 \\
\hline 11 & $\begin{array}{r}24 \text { Jan } \\
2016\end{array}$ & 1.008 & 248 & 144 & 168 & 1.568 \\
\hline 12 & $\begin{array}{r}25 \text { Jan } \\
2016\end{array}$ & 636 & 68 & 80 & 40 & 824 \\
\hline 13 & $\begin{array}{r}26 \text { Jan } \\
2016\end{array}$ & 4.016 & 400 & 240 & 240 & 4.896 \\
\hline 14 & $\begin{array}{r}17 \text { Feb } \\
2016\end{array}$ & 4.816 & 788 & 164 & 188 & 5.956 \\
\hline 15 & $\begin{array}{r}18 \text { Feb } \\
2016\end{array}$ & 2.720 & 1.140 & 284 & 292 & 4.436 \\
\hline 16 & $\begin{array}{r}19 \text { Feb } \\
2016\end{array}$ & 244 & 64 & 16 & 24 & 348 \\
\hline 17 & $\begin{array}{r}21 \text { Feb } \\
2016\end{array}$ & 2.548 & 884 & 1040 & 112 & 4.584 \\
\hline 18 & $\begin{array}{r}22 \text { Feb } \\
2016\end{array}$ & 12.636 & 2.748 & 2182 & 940 & 18.506 \\
\hline \multirow[t]{2}{*}{19} & $\begin{array}{r}23 \text { Feb } \\
2016 \\
\end{array}$ & 3.136 & 316 & 296 & 280 & 4.028 \\
\hline & Jumlah & 59.040 & 12.416 & 6.058 & 3.840 & 81.354 \\
\hline
\end{tabular}

Dari Tabel 1 dapat dilihat produk yang baik dan cacat, dimana produk dengan KW 1 adalah produk yang tanpa cacat, sedangkan KW 2 dan KW 3 adalah produk cacat namun dapat dijual. Sedangkan produk reject tidak dapat dijual namun dapat dijadikan produk list. Berikut bentuk produk cacat.

Tabel 2. Data produk Perth PX KW 2

\begin{tabular}{|c|c|c|c|c|c|c|}
\hline \multirow{2}{*}{ No } & \multirow{2}{*}{ Tanggal } & \multirow{2}{*}{ KW2 } & \multicolumn{4}{|c|}{ Jenis Defect } \\
\hline & & & CK & $\mathrm{CM}$ & $\mathrm{CP}$ & Lam \\
\hline 1 & $\begin{array}{r}11 \text { Jan } \\
2016\end{array}$ & 56 & 50 & 6 & 0 & 0 \\
\hline 2 & $\begin{array}{r}12 \text { Jan } \\
2016\end{array}$ & 1.024 & 735 & 208 & 48 & 33 \\
\hline 3 & $\begin{array}{r}15 \text { Jan } \\
2016\end{array}$ & 308 & 206 & 81 & 21 & 0 \\
\hline
\end{tabular}


Lanjutan Tabel 2. Data produk Perth PX KW 2

\begin{tabular}{|c|c|c|c|c|c|c|}
\hline \multirow{2}{*}{ No } & \multirow{2}{*}{ Tanggal } & \multirow{2}{*}{ KW2 } & \multicolumn{4}{|c|}{ Jenis Defect } \\
\hline & & & CK & $\mathrm{CM}$ & $\mathrm{CP}$ & Lam \\
\hline 4 & $\begin{array}{r}16 \text { Jan } \\
2016\end{array}$ & 292 & 200 & 84 & 7 & 1 \\
\hline 5 & $\begin{array}{r}18 \text { Jan } \\
2016\end{array}$ & 644 & 574 & 52 & 11 & 7 \\
\hline 6 & $\begin{array}{r}19 \text { Jan } \\
2016\end{array}$ & 2548 & 2345 & 175 & 26 & 2 \\
\hline 7 & $\begin{array}{r}20 \text { Jan } \\
2016\end{array}$ & 372 & 301 & 3 & 33 & 35 \\
\hline 8 & $\begin{array}{r}21 \text { Jan } \\
2016\end{array}$ & 84 & 54 & 0 & 15 & 15 \\
\hline 9 & $\begin{array}{r}22 \text { Jan } \\
2016\end{array}$ & 0 & 0 & 0 & 0 & 0 \\
\hline 10 & $\begin{array}{r}23 \text { Jan } \\
2016\end{array}$ & 432 & 256 & 129 & 32 & 15 \\
\hline 11 & $\begin{array}{r}24 \text { Jan } \\
2016\end{array}$ & 248 & 230 & 11 & 7 & 0 \\
\hline 12 & $\begin{array}{r}25 \text { Jan } \\
2016\end{array}$ & 68 & 31 & 10 & 13 & 14 \\
\hline 13 & $\begin{array}{r}26 \text { Jan } \\
2016\end{array}$ & 400 & 254 & 124 & 22 & 0 \\
\hline 14 & $\begin{array}{r}17 \text { Feb } \\
2016\end{array}$ & 788 & 543 & 163 & 67 & 15 \\
\hline 15 & $\begin{array}{r}18 \text { Feb } \\
2016\end{array}$ & 1.140 & 931 & 153 & 52 & 4 \\
\hline 16 & $\begin{array}{r}19 \text { Feb } \\
2016\end{array}$ & 64 & 45 & 19 & 0 & 0 \\
\hline 17 & $\begin{array}{r}21 \text { Feb } \\
2016\end{array}$ & 884 & 617 & 262 & 2 & 3 \\
\hline 18 & $\begin{array}{r}22 \text { Feb } \\
2016\end{array}$ & 2.748 & 2.188 & 447 & 103 & 10 \\
\hline 19 & $\begin{array}{r}23 \text { Feb } \\
2016 \\
\end{array}$ & 316 & 263 & 5 & 43 & 5 \\
\hline & Jumlah & 12.416 & 9.823 & 1.932 & 502 & 159 \\
\hline
\end{tabular}

Tabel 3. Data Produk Perth PX KW 3

\begin{tabular}{|c|c|c|c|c|c|c|c|}
\hline \multirow{2}{*}{ No } & \multirow{2}{*}{ Tanggal } & \multirow{2}{*}{ KW3 } & \multicolumn{5}{|c|}{ Jenis Defect } \\
\hline & & & CK & $\mathrm{CM}$ & $\mathrm{CP}$ & Lam & $\mathrm{BL}$ \\
\hline 1 & $\begin{array}{r}11 \text { Jan } \\
2016\end{array}$ & 4 & 0 & 0 & 0 & 4 & \\
\hline 2 & $\begin{array}{r}12 \text { Jan } \\
2016\end{array}$ & 14 & 0 & 5 & 207 & 132 & \\
\hline 3 & $\begin{array}{r}15 \text { Jan } \\
2016\end{array}$ & 244 & 0 & 0 & 230 & 14 & \\
\hline 4 & $\begin{array}{r}16 \text { Jan } \\
2016\end{array}$ & 168 & 0 & 0 & 147 & 21 & \\
\hline 5 & $\begin{array}{r}18 \text { Jan } \\
2016\end{array}$ & 6 & 0 & 0 & 61 & 15 & \\
\hline 6 & $\begin{array}{r}19 \text { Jan } \\
2016\end{array}$ & 336 & 47 & 0 & 263 & 26 & \\
\hline 7 & $\begin{array}{r}20 \text { Jan } \\
2016\end{array}$ & 4 & 8 & 0 & 76 & 80 & \\
\hline 8 & $\begin{array}{r}21 \text { Jan } \\
2016\end{array}$ & 76 & 2 & 0 & 55 & 19 & \\
\hline 9 & $\begin{array}{r}22 \text { Jan } \\
2016\end{array}$ & 8 & 0 & 0 & 5 & 3 & \\
\hline
\end{tabular}

Lanjutan Tabel 3. Data Produk Perth PX KW 3

\begin{tabular}{|c|c|c|c|c|c|c|c|}
\hline \multirow{2}{*}{ No } & \multirow{2}{*}{ Tanggal } & \multirow{2}{*}{ KW3 } & \multicolumn{5}{|c|}{ Jenis Defect } \\
\hline & & & CK & CM & $\mathrm{CP}$ & Lam & $\mathrm{BL}$ \\
\hline 10 & $\begin{array}{r}23 \text { Jan } \\
2016\end{array}$ & 192 & 40 & 0 & 70 & 82 & 0 \\
\hline 11 & $\begin{array}{r}24 \text { Jan } \\
2016\end{array}$ & 144 & 87 & 0 & 7 & 50 & 0 \\
\hline 12 & $\begin{array}{r}25 \text { Jan } \\
2016\end{array}$ & 80 & 0 & 0 & 53 & 27 & 0 \\
\hline 13 & $\begin{array}{r}26 \text { Jan } \\
2016\end{array}$ & 240 & 0 & 0 & 150 & 90 & \\
\hline 14 & $\begin{array}{r}17 \text { Feb } \\
2016\end{array}$ & 164 & 7 & 0 & 137 & 20 & 0 \\
\hline 15 & $\begin{array}{r}18 \text { Feb } \\
2016\end{array}$ & 284 & 5 & 0 & 126 & 100 & 53 \\
\hline 16 & $\begin{array}{r}19 \text { Feb } \\
2016\end{array}$ & 16 & 0 & 0 & 10 & 6 & \\
\hline 17 & $\begin{array}{r}21 \text { Feb } \\
2016\end{array}$ & 1.040 & 31 & 0 & 251 & 70 & 688 \\
\hline 18 & $\begin{array}{r}22 \text { Feb } \\
2016\end{array}$ & 2.192 & 49 & 0 & 385 & 423 & 1.335 \\
\hline 19 & $\begin{array}{r}23 \text { Feb } \\
2016 \\
\end{array}$ & 296 & 24 & 0 & 74 & 24 & 174 \\
\hline & mlah & 6.068 & 300 & 5 & 2.307 & 1.206 & 2.250 \\
\hline
\end{tabular}

Tabel 4. Data Produk Perth PX Reject

\begin{tabular}{|c|c|c|c|c|c|c|}
\hline \multirow{2}{*}{ No } & \multirow{2}{*}{ Tanggal } & \multirow{2}{*}{ Reject } & \multicolumn{4}{|c|}{ Jenis Defect } \\
\hline & & & CK & $\mathrm{CM}$ & $\mathrm{CP}$ & Lam \\
\hline 1 & $\begin{array}{r}11 \text { Jan } \\
2016\end{array}$ & 16 & 0 & 0 & 8 & 8 \\
\hline 2 & $\begin{array}{r}12 \text { Jan } \\
2016\end{array}$ & 228 & 0 & 0 & 127 & 101 \\
\hline 3 & $\begin{array}{r}15 \text { Jan } \\
2016\end{array}$ & 120 & 0 & 0 & 70 & 50 \\
\hline 4 & $\begin{array}{r}16 \text { Jan } \\
2016\end{array}$ & 100 & 0 & 0 & 65 & 35 \\
\hline 5 & $\begin{array}{r}18 \text { Jan } \\
2016\end{array}$ & 140 & 0 & 0 & 78 & 62 \\
\hline 6 & $\begin{array}{r}19 \text { Jan } \\
2016\end{array}$ & 332 & 0 & 0 & 212 & 120 \\
\hline 7 & $\begin{array}{r}20 \text { Jan } \\
2016\end{array}$ & 164 & 0 & 0 & 110 & 54 \\
\hline 8 & $\begin{array}{r}21 \text { Jan } \\
2016\end{array}$ & 200 & 0 & 0 & 127 & 73 \\
\hline 9 & $\begin{array}{r}22 \text { Jan } \\
2016\end{array}$ & 16 & 0 & 0 & 16 & 0 \\
\hline 10 & $\begin{array}{r}23 \text { Jan } \\
2016\end{array}$ & 240 & 0 & 0 & 80 & 160 \\
\hline 11 & $\begin{array}{r}24 \text { Jan } \\
2016\end{array}$ & 168 & 0 & 0 & 68 & 100 \\
\hline 12 & $\begin{array}{r}25 \text { Jan } \\
2016\end{array}$ & 40 & 0 & 0 & 26 & 14 \\
\hline 13 & $\begin{array}{r}26 \text { Jan } \\
2016\end{array}$ & 240 & 0 & 0 & 120 & 120 \\
\hline 14 & $\begin{array}{r}17 \text { Feb } \\
2016\end{array}$ & 188 & 0 & 0 & 124 & 64 \\
\hline 15 & $\begin{array}{r}18 \text { Feb } \\
2016 \\
\end{array}$ & 292 & 0 & 0 & 186 & 106 \\
\hline
\end{tabular}


Lanjutan Tabel 4. Data Produk Perth PX Reject

\begin{tabular}{|c|c|c|c|c|c|c|}
\hline \multirow{2}{*}{ No } & \multirow{2}{*}{ Tanggal } & \multirow{2}{*}{ Reject } & \multicolumn{4}{|c|}{ Jenis Defect } \\
\hline & & & CK & CM & $\mathrm{CP}$ & Lam \\
\hline 16 & $\begin{array}{r}19 \text { Feb } \\
2016\end{array}$ & 24 & 0 & 0 & 15 & 9 \\
\hline 17 & $\begin{array}{r}21 \text { Feb } \\
2016\end{array}$ & 2 & 0 & 0 & 65 & 47 \\
\hline 18 & $\begin{array}{r}22 \text { Feb } \\
2016\end{array}$ & 0 & 0 & 0 & 423 & 517 \\
\hline 19 & $\begin{array}{r}23 \text { Feb } \\
2016 \\
\end{array}$ & 0 & 0 & 0 & 190 & 90 \\
\hline & & 840 & & & 110 & 1.730 \\
\hline
\end{tabular}

Setelah mendatakan berbagai data defect produk Perth PX saat proses disortir pacs, maka selanjutnya menganalisis produk cacat yang ada dengan menggunakan metode diagram pareto dan analisis diagram sebab akibat.

Berikut adalah Tabel hasil perhitungan untuk diagram pareto berdasarkan jenis defect pada produk Perth PX. Di departemen QA pada bulan Januari dan Februari 2016.

Pada Gambar 2 dapat dilihat persentase cacat adalah defect cekung, chipping, dan laminasi, belang dan cembung. Dari data tersebut diambil 3 cacat terbesar yaitu cekung, chipping, dan laminasi. Karena defect yang sangat besar dan perlu diperbaiki unjuk menjamin mutu produk Perth PX.

\section{Proses Inspeksi Produk di PT Asri Pancawarna}

Pada proses inspeksi dilakukan oleh beberapa divisi, yaitu divisi R\&D, divisi PPC, dan divisi QA. Dimana setiap divisi berfungsi sama yaitu untuk menjamin mutu produk namun tujuan dilakukannya berbeda. Divisi R\&D melakukan inspeksi untuk melihat kesesuaian produk dari formula yang telah di buat. Divisi PPC melakukan inspeksi untuk melihat kesuaian produk yang telah direncanakan. Sedangkan divisi QA melakukan inspeksi untuk menjamin mutu produk langsung ke tangan konsumen. Berikut ini alur proses inspeksi produk yang dilakukan di PT. Asri Pancawarna.

\section{Inspeksi pada Area Body Preparation}

Inspeksi ini merupakan inspeksi pada proses pembuatan bahan utama keramik yaitu pembuatan slip yang selanjutnya akan di bentuk menjadi bubuk powder. Proses inspeksi dilakukan oleh divisi R\&D karena divisi ini bertanggung jawab atas formula yang dibuat dan sebagai salah satu catatan histori untuk divisi R\&D.

Tabel 5. Perhitungan untuk Diagram Pareto Produk Perth PX

\begin{tabular}{clrrrr}
\hline No & Jenis Reject & \multicolumn{1}{c}{ Jumlah } & \multicolumn{1}{c}{ Kumulatif } & \% Persentase & \% Komulatif \\
\hline 1 & Cekung & 10123 & 10123 & 45,35 & 45,35 \\
2 & Chipping & 4919 & 16979 & 22,03 & 67,38 \\
3 & Laminasi & 3095 & 20074 & 13,86 & 81,24 \\
4 & Belang & 2250 & 22324 & 10,08 & 91,32 \\
5 & Cembung & 1937 & 12060 & 8,68 & 100 \\
\hline
\end{tabular}

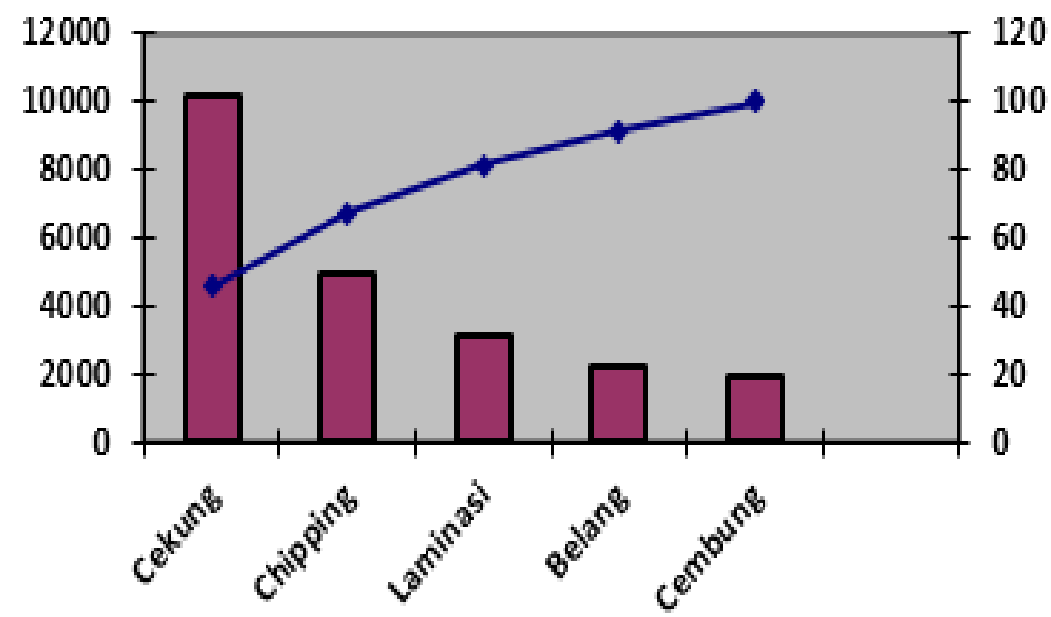

Gambar 2. Diagram Pareto Produk Perth PX 


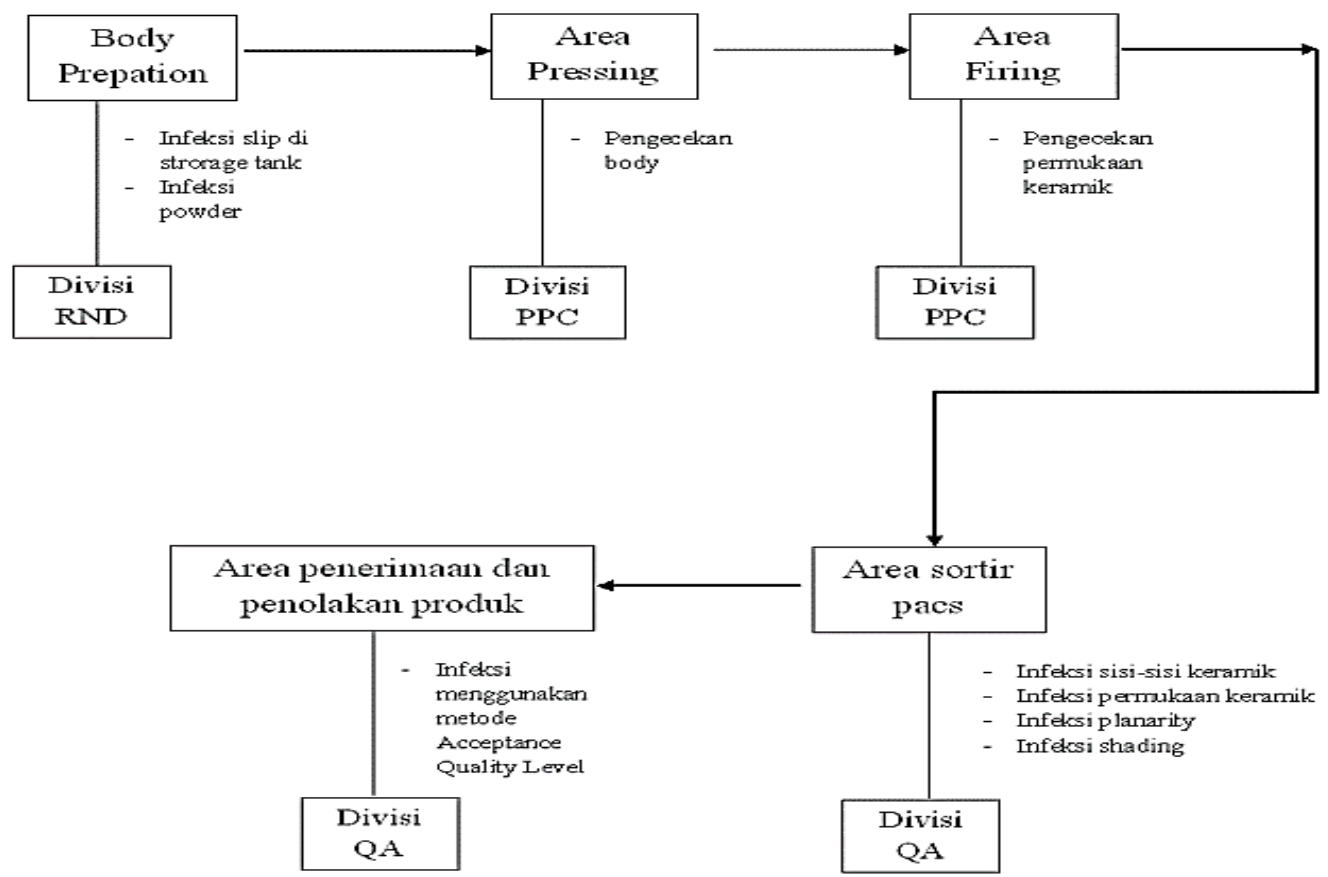

Gambar 3. Alur Proses Inspeksi di PT. Asri Pancawarna

Pada saat pembuatan slip kegiatan yang inspeksi adalah kadar warna slip pada storage tank. Agar warna bubuk powder setelah proses slip di-spray sesuai dengan warna yang diinginkan. Selanjutnya adalah proses inspeksi pada bubuk powder yaitu inspeksi kadar air dalam powder. Karena bila powder mempunyai kadar air yang masih tinggi maka pada saat proses pengepressan cetakan press akan lengket dan merusak bentuk keramik. Namun bila kadar air terlalu rendah maka powder akan sulit dibentuk atau sulit menyatu setelah di press. Sehingga pengaturan mesin spray harus di perhatikan sehingga powder yang dihasilkan sesuai dengan standar.

\section{Inspeksi pada Area Pressing}

Inspeksi ini merupakan inspeksi pada proses pembentukan body keramik. Proses inspeksi dilakukan oleh divisi PPC karena divisi ini bertanggung jawab atas bentuk permukaan keramik yang sesuai dengan perencanaan.

Inspeksi ini hanya melihat hasil press dan bentuk permukaan dengan cara mengerok permukaan keramik agar terlihat bentuk permukaan.

\section{Inspeksi pada Area Firing}

Inspeksi ini merupakan inspeksi pada proses pembakaran keramik. Proses inspeksi dilakukan bertujuan untuk melihat hasil pembakaran keramik. Inspeksi yang dilakukan adalah pengecekan planarity dan sisi-sisi keramik hasil pembakaran. Dan mencatat history pembakaran sebelumnya untuk memperbaiki proses pembakaran ke depan.

\section{Inspeksi pada Area Sortir Pacs}

Inspeksi ini merupakan inspeksi yang banyak dilakukan karena diproses ini adalah proses akhir dari pembuatan keramik. Beberapa inspeksi yang ada pada proses ini adalah:

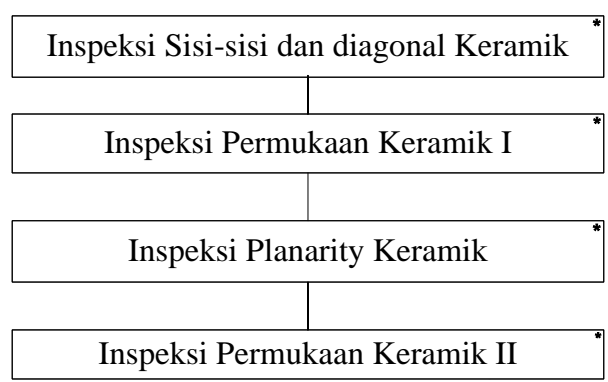

Gambar 4. Alur Proses Inspeksi Area Sortir Pacs

Inspeksi Sisi-sisi dan Diagonal Keramik

Inspeksi sisi-sisi dan diagonal keramik adalah memonitoring keramik yang sedang berjalan setelah proses pre squering untuk melihat hasil pemotongan sisi-sisi keramik untuk menjamin sisi keramik sesuai dengan 
ukuran standard yaitu $59.6 \mathrm{~cm}$. Bila ukuran lebih dari $59.6 \mathrm{~cm}$ maka keramik tersebut diambil dan diproses ulang untuk dipotong sesuai dengan ukuran standard. Tapi bila ukuran kurang dari $59.6 \mathrm{~cm}$ maka keramik akan diberi tanda.

\section{Inspeksi permukaan Keramik I}

Monitoring permukaan keramik untuk melihat kecerahan keramik setelah proses polesing oleh mesin polesing dengan batu abrasive. Dengan kecerahan 55-60 . Bila terdapat kecerahan keramik kurang dari standard maka keramik akan diambil dan diproses ulang di mesin polesing.

\section{Inspeksi Planarity Keramik}

Inspeksi palanarity keramik yaitu untuk melihat kecekungan atau kecembungan permukaan dan sisi keramik. Untuk permukaan keramik batas toleransi adalah $\pm 0.8 \mathrm{~cm}$ sedangkan untuk sisi keramik batas toleransi adalah $\pm 0.6 \mathrm{~cm}$. Bila terdapat keramik yang tidak memenuhi standar maka keramik tersebut akan di beri tanda.

\section{Inspeksi Permukaan Keramik II}

Inspeksi permukaan keramik II yaitu untuk melihat kecerahan keramik setelah proses Nano oleh mesin Nano dengan proses Chemical Nano. Dengan kecerahan min $88^{\circ}$. Bila terdapat kecerahan keramik kurang dari standard maka keramik akan diambil dan diproses ulang di mesin nano. Selain itu monitoring ini bertugas melihat shading dan corak pada permukaan keramik, karena setiap permukaan keramik glossi tidaklah sama persis namun ada perbedaan-perbedaan motiv dan kecerahan warna. Bila terdapat kecerahan yang berbeda maka akan diberi tanda shading yang berbeda. Begitu pula dengan corak, bila terdapat corak yang sangat berbeda maka akan diberi tanda pada corak tersebut. Selanjutnya akan dilihat didivisi QA bagian penerimaan dan penolakan produk. Selain itu inspeksi ini adalah penentu produk KW 1, KW 2 dan KW 3.

Setelah produk melewati proses monitoring produk tersebut akan dikemas dalam box. Dengan isi 4 pc setiap box. Dan sebelum dikemas masing-masing produk telah diberi tanda produk KW 1, KW 2 ,dan KW 3. Setelah dikemas dalam box. Box tersebut dikumpulkan dalam 1 pallet dengan kuantitas 1 pallet berisi 36 box. Selanjutnya pallet tersebut ditaruh di tempat penyimpanan sementara untuk dicek di divisi penerimaan dan penolakan produk oleh tim Quality Assurance untuk menjamin mutu sebelum produk ketangan konsumen atau masuk gudang sebagai inventory.

Pada inspeksi di area sortir pacs ini akan terlihat produk mana yang cacat dan tidak. Karena pada proses sebelumnya belum bisa dilihat kecacatan produk karena permukaan keramik masih sama. Dan setelah melewati proses di area sortir pacs maka dapat terlihat jenis-jenis cacat yang ada. Dan dapat dilihat cacat yang di sebabkan oleh proses sebelumnya.

\section{AQL Proces}

Inspeksi Proses penerimaan dan penolakan produk dengan system Acceptance Quality Level adalah proses untuk produk diterima yang selanjutnya dapat diberikan ke tangan konsumen atau menolak produk karena terdapat produk yang tidak sesuai dengan ketentuan yang berlaku dalam system Acceptancce Quality Level.

\section{Analisis Penyebab Cacat}

Analisis diagram sebab akibat digunakan untuk mengetahui sebab terjadinya masalah defect pada produk yang diamati dengan mengumpulkan dan megelompokkannya dalam beberapa penyebab dari faktor produksi, analisis ini berhubungan langsung dengan pengaruh faktor-faktor produksi diantaranya, manusia/operator, mesin, bahan baku/material, metode dan faktor non teknis lainnya yang kurang maksimal sehingga perlu diadakannya rencana solusi perbaikan untuk menghilangkan atau paling tidak mengurangi akibat yang terjadi.

Dari hasil analisis diagram pareto di atas dapat diketahui sebab yang utama dalam terjadinya produk reject adalah jenis defect permukaan keramik cekung pada produk Perth PX dengan persentase yang cukup besar yakni mencapai 45,35\% dan jenis defect chipping dengan prentase 22,03\%. Maka sebagai langkah awal yang harus dilakukan adalah jadikan jenis 


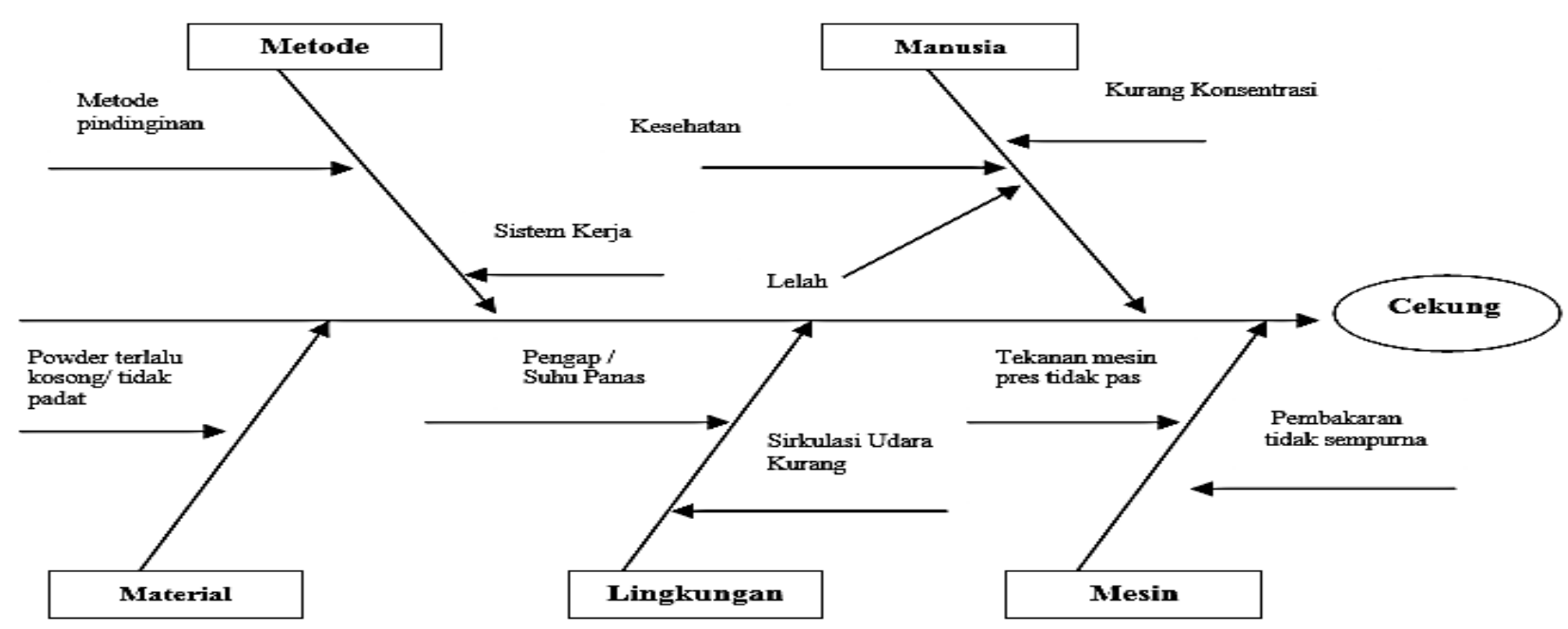

Gambar 5. Diagram Sebab Akibat Defect Cekung

cacat pakan tebal sebagai prioritas utama yang harus segera ditindak lanjuti. Maka untuk mengatasi masalah jenis cacat pakan tebal tersebut, kita harus menganalisis dengan diagram sebab akibat/fishbone seperti pada Gambar 5.

Faktor penyebab masalah yang terjadi pada Gambar 5 dapat diuraikan sebagai berikut:

\section{Faktor Manusia}

Faktor manusia sangat berperan aktif dalam produksi yang dihasilkan, karena manusia bertindak sebagai operator, walaupun pengerjaan pembuatan produk dilakukan oleh mesin, tetapi manusia juga sangat mempengaruhi dalam pembuatan produk. Bagus atau buruknya produk yang dihasilkan ditentuakan oleh operator, hal ini dapat dipengaruhi oleh beberapa sebab yaitu:

1. Operator kemungkinan saat bekerja tidak konsentrasi sehingga hasil yang diperoleh tidak sesuai.

2. Keterampilan tiap operator satu dengan operator lainnya berbeda, ada operator yang mungkin kurang terampil, sehingga produk yang dihasilkan tidak sesuai.

3. Kesehatan Operator kadang kala kurang memadai untuk melakukan kegiatan kerja, yang mungkin akibat kelelahan yang berlebihan akibat beban kerja yang terlalu banyak. Atau juga operator mengalami pusing, karena berdiri terlalu lama saat bekerja.

\section{Faktor Mesin}

Mesin yang diguanakan biasanya dapat menyebabkan beberapa kesalahan, kesalahan tersebut dapat terjadi diantaranya:

1. Pembakaran tidak sempurna disebabkan api pada mesin kiln tidak merata atau api pada mesin kiln terlalu panas sehingga mengakibatkan terlalu melelehnya permukaan keramik sehingga permukaan keramik menjadi cekung.

2. Tekanan mesin pres tidak pas, sehingga mengakibatkan udara dalam powder tidak keluar sehingga pada saat di bakar mengakibatkan permukaan cekung.

\section{Faktor Metode}

Pada faktor metode, disebabkan karena mungkin kurangnya pengawasan atasan pada proses produksi, yang membuat moral kerja para karyawan kurang baik dalam bekerja. Dimana kurangnya pengawasan tersebut akan menyebabkan sistem kerja yang sudah tercantum dalam SOP tidak diaplikasikan secara penuh. Semua itu akan mempengaruhi hasil produk yang diproduksi.

\section{Faktor Material}

Bahan baku yang digunakan dalam produksi, dalam hal ini adalah powder yang merupakan komponen utama pembuatan produk jika kualitasnya kurang bagus dimana powder tersebut terlalu kering atau basah, akan mengakibatkan pada saat proses pembakaran permukaan keramik cekung. 


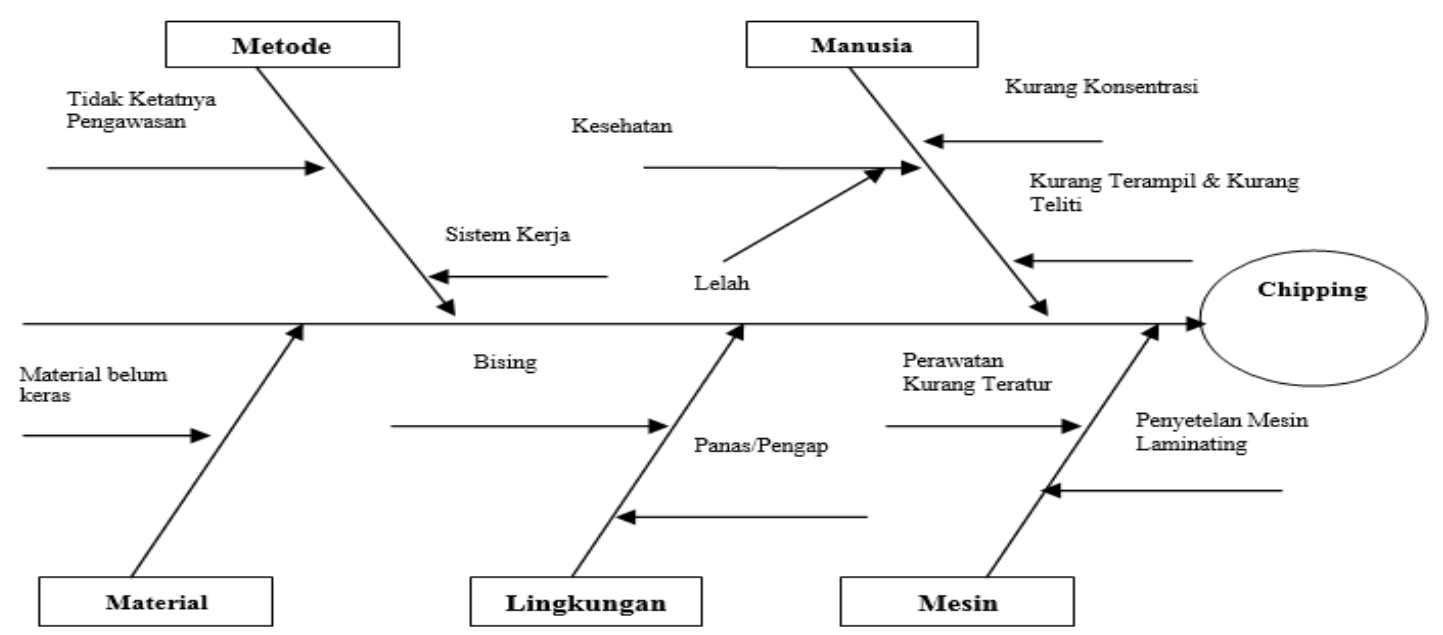

Gambar 6. Diagram Sebab Akibat Defect Chipping

\section{Faktor Lingkungan}

Dimana faktor lingkungan akan mempengaruhi kegiatan produksi. seperti sebagai berikut:

1. Ruangan departemen produksi yang terlalu pengap, atau suhu udara yang sangat panas, karena pengaruh mesin yang beroperasi. Dimana hal tersebut akan mempengaruhi kinerja para karyawan dalam proses produksi, yang akibatnya produk yang dihasilkan tidak sesuai.

2. Sirkulasi udara yang kurang, yang terjadi akibat kurangnya fentilasi uadara pada ruangan departemen produksi. Dimana akan mengakibatkan konsentarsi para karyawan menurun dan menghasilkan produk yang tidak sesuai.

Faktor penyebab masalah yang terjadi pada Gambar 6 dapat diuraikan sebagai berikut:

\section{Faktor Manusia}

Faktor manusia sangat berperan aktif dalam produksi yang dihasilkan, karena manusia bertindak sebagai operator, walaupun pengerjaan pembuatan produk dilakukan oleh mesin, tetapi manusia juga sangat mempengaruhi dalam pembuatan produk. Bagus atau buruknya produk yang dihasilkan ditentuakan oleh operator, hal ini dapat dipengaruhi oleh beberapa sebab yaitu:

1. Operator kemungkinan saat bekerja tidak konsentrasi sehingga hasil yang diperoleh tidak sesuai.
2. Keterampilan tiap operator satu dengan operator lainnya berbeda, ada operator yang mungkin kurang terampil, sehingga produk yang dihasilkan tidak sesuai. Kurangnya ketelitian tiap operator juga berbeda, yang mengakibatkan hasil produksi yang tidak sesuai.

3. Kesehatan Operator kadang kala kurang memadai untuk melakukan kegiatan kerja, yang mungkin akibat kelelahan yang berlebihan akibat beban kerja yang terlalu banyak. Atau juga operator mengalami pusing, karena berdiri terlalu lama saat bekerja.

\section{Faktor Mesin}

Mesin yang digunakan biasanya dapat menyebabkan beberapa kesalahan, kesalahan tersebut dapat terjadi diantaranya:

1. Perawatan yang kurang teratur biasanya akan mengakibatkan kemampuan mesin dalam poses produksi berkurang. Contoh akibatnya kecepatan conveyor berubah menjadi cepat sehingga terjadi benturan antara keramik dengan dinding-dinding mesin sehingga menyebabkan sudut-sudut keramik patah atau menjadi chipping.

2. Penyetelan mesin laminating yang tidak akurat juga akan mengakibatkan hasil produksi tidak sesuai. Contohnya pada saat pemolesan tekanan batu abrasive terlalu kencang sehingga sudut-sudut keramik tidak kuat menahan tekanan tersebut maka sudut keramik tersebut patah. 


\section{Faktor Metode}

Pada faktor metode, disebabkan karena mungkin kurangnya pengawasan atasan pada proses produksi, yang membuat moral kerja para karyawan kurang baik dalam bekerja. Dimana kurangnya pengawasan tersebut akan menyebabkan sistem kerja yang sudah tercantum dalam SOP tidak diaplikasikan secara penuh. Semua itu akan mempengaruhi hasil produk yang diproduksi.

\section{Faktor Material}

Bahan baku yang digunakan dalam produksi, dalam hal ini adalah powder yang dibuat pada area ball mill yang merupakan komponen utama pembuatan produk jika kualitasnya kurang bagus akan mengakibatkan produk tidak sesuai, kesalahan tersebut terjadi karena pengeringan powder yang tidak sempurna mengakibatkan pada saat terjadi benturan powder tidak terlalu mengikat sehingga mudah retak atau patah ketika terjadi benturan.

\section{Faktor Lingkungan}

Dimana faktor lingkungan akan mempengaruhi kegiatan produksi seperti sebagai berikut:

1. Suara bising dapat mempengaruhi konsentrasi karyawan, dan dilihat dari segi kesehatan akan menimbulkan efek gangguan pendengaran dalam jangku waktu lama. Hal tersebut jelas akan mempengaruhi kinerja karyawan dan menghasilkan produk yang tidak sesuai. Karena instruksi dari supervisor tidak terdengar jelas sehingga pada saat penanganan tidak terlambat.

2. Ruangan produksi yang memliki suhu panas/pengap akan mengakibatkan konsentarsi para karyawan menurun dan menghasilkan produk yang tidak sesuai.

\section{Usulan Perbaikan}

Dari diagram sebab-akibat tersebut dapat diberikan usulan perbaikan untuk mengurangi cacat-cacat yang sangat mempengaruhi penjaminan mutu produk kepada konsumen. Karena yang mempunyai tingkat kecacatan paling besar merupakan masalah yang menjadi prioritas untuk terlebih dahulu dipecahkan, agar perusahaaan dapat mencari solusi terbaik untuk menangani tingkat kecacatan yang besar tersebut.

Agar lebih maksimal dalam menangani permasalahan tingkat kecacatan pada produk Perth PX, secara continiu dapat dilakukan beberapa usulan perbaikan sebagai berikut :

\section{Usulan Perbaikan Cacat Cekung pada Produk Perth}

Perbaikan untuk cacat cekung dapat dilakukan dengan usulan sebagai berikut:

1. Mengatur tekanan mesin press sesuai dengan SOP sebelum pengoperasian. Agar udara pada saat pengepresan tahap 1 sampai 3 tidak ada yag terjebak.

2. Mengatur suhu pada mesin Kiln untuk tetap stabil, agar tidak terjadi pemanasan yang tidak merata atau hanya matang dipermukaan saja namun tidak di dalam permukaan keramik, karena hal ini dapat menyebabkan permukaan keramik akan menurun atau menjadi cekung pada saat proses pendinginan atau pada saat proses polessing.

3. Pada saat proses pendinginan di usahakan didinginkan selama 1 shift, hal ini bertujuan agar keramik semua benar-benar matang. Sehingga saat proses polessing permukaan keramik tidak mengalami penurunan/cekung karena keramik yang masih lembek akibat dari pembakaran.

4. Para pekerja diarea sortir pacs dan firing harus saling melakukan kordinasi dan briefing setiap melakukan pekerjaan. Agar tidak terjadi kesalahan mengambil keramik yang sudah didinginkan selama 1 shift dengan keramik yang baru didinginkan.

5. Selama proses berlangsung, para supervisor wajib melakukan pengawasan dan pemeriksaan secara ketat dan continiu terhadap stasiun-stasiun kerja yang menjadi tanggung jawabnya.

6. Selain preventive maintanance dan membersihkan mesin yang dilakukan sebulan sekali, setiap waktu selama proses berlangsung mekanik juga wajib berkeliling mengecek bagian-bagian mesin yang rentan atau aus yang sekiranya mudah rusak dan perlu perawatan khusus. 


\section{Usulan Perbaikan Cacat Chipping pada Produk Perth PX}

Perbaikan untuk cacat chipping dapat dilakukan dengan usulan sebagai berikut:

1. Pengaturan kecepatan lintasan keramik harus diperhatikan, dihindari proses menabrak dinding-dinding pembatas lintasan terlalu kencang. Karena dapat menyebabkan sudut-sudut keramik menjadi patah.

2. Memeriksa tekanan mesin polesing dan ketebalan batunya, untuk menghindari retak pada sudut-sudut keramik.

3. Memeriksa pahatan mesin pemotong agar tidak terjadi aus, karena bila pahat mesin potong aus maka sudut-sudut keramik tidak bagus perataannya sehingga dapat berdampak sudut keramik menjadi patah sudut-sudut keramik menjadi.

4. Selama proses berlangsung, para supervisor wajib melakukan pengawasan dan pemeriksaan secara ketat dan kontinu terhadap stasiun-stasiun kerja yang menjadi tanggung jawabnya.

5. Selain preventive maintanance dan membersihkan mesin yang dilakukan sebulan sekali, setiap waktu selama proses berlangsung mekanik juga wajib berkeliling mengecek bagian-bagian mesin yang rentan atau aus yang sekiranya mudah rusak dan perlu perawatan khusus.

\section{KESIMPULAN}

Berdasarkan pengumpulan dan analisis data yang telah dilakukan, maka dapat diambil kesimpulan: terdapat lima jenis cacat/defect yang ada di departemen Quality Assurance yaitu, jenis cacat Cekung, chipping, Lainasi, Belang dan Cembung. Jenis cacat yang paling dominan adalah jenis cekung dengan persentase yang cukup besar yaitu mencapai 45,35\% untuk produk Pert PX. Penyebab utamanya adalah karena material powder yang masih ada kadar air, udara yang masih terperangkap dalam keramik, proses pembakaran yang tidak merata serta suhunya terlalu tinggi dan proses pendinginan yang tidak berlangsung lama sehingga pada proses polessing permukaan keramik menjadi turun/cekung. Solusi yang bisa diterapkan untuk menanggulangi faktor manusia diantaranya dengan melakukan pelatihan yang teratur secara berkala, memilih operator yang masih muda dengan tingkat ketelitian yang masih baik. Serta lingkungan atau ruangan yang mendukung seperti, pencahayaan dan temperatur ruang yang baik serta mengurangi tingkat kebisingan.

\section{DAFTAR PUSTAKA}

[1] Feigenbaum, Armand Vallin (1961), Total Quality Control, McGraw-Hill $\backslash$

[2] Juran, Joseph M., ed. (1995), A History of Managing for Quality: The Evolution, Trends, and Future Directions of Managing for Quality, Milwaukee, Wisconsin: The: American Society for Quality Control, ISBN 9780873893411, OCLC 32394752

[3] Suwitono. 2008. Pengenalan Departemen Produksi. PT. Asri Pancawarna

[4] Setiadi, Dede. 2006. Pengertian ISO 900 Sistem Standar Manajemen Mutu. Materi pada acara Pelatihan Audit Lingkungan yang diadakan oleh Departemen Biologi FMIPA IPB dan PKSDM Ditjen DIKTI DEPDIKNAS di Graha Dinar- Cisarua. 